\title{
Vitamin D serostatus and dengue fever progression to dengue hemorrhagic fever/dengue shock syndrome
}

\author{
E. VILLAMOR ${ }^{1 *}$, L. A. VILLAR ${ }^{2}$, A. LOZANO ${ }^{2}$, V. M. HERRERA ${ }^{2}$ AND \\ O. F. HERRÁN ${ }^{2}$ \\ ${ }^{1}$ Department of Epidemiology, University of Michigan School of Public Health, Ann Arbor, MI, USA \\ ${ }^{2}$ Faculty of Health, Centre for Epidemiological Investigations, Industrial University of Santander, Bucaramanga, \\ Colombia
}

Received 12 June 2017; Final revision 19 July 2017; Accepted 17 August 2017;

first published online 14 September 2017

\section{SUMMARY}

Vitamin D could modulate pathways leading to dengue hemorrhagic fever/dengue shock syndrome (DHF/DSS). We examined the associations of serum total 25 -hydroxy vitamin D $[25(\mathrm{OH}) \mathrm{D}]$ and vitamin D binding protein (VDBP) concentrations in patients with uncomplicated dengue fever (DF) with risk of progression to DHF/DSS. In a case-control study nested in a cohort of DF patients who were followed during the acute episode in Bucaramanga, Colombia, we compared 25(OH)D and VDBP at onset of fever between 110 cases who progressed to DHF/ DSS and 235 DF controls who did not progress. 25(OH)D concentrations were also compared between the acute sample and a sample collected $>1$ year post-convalescence in a subgroup. Compared with $25(\mathrm{OH}) \mathrm{D} \geqslant 75 \mathrm{nmol} / \mathrm{l}$, adjusted odds ratios $(95 \% \mathrm{CI})$ for progression were 0.44 $(0 \cdot 22-0 \cdot 88)$ and $0.13(0 \cdot 02-1 \cdot 05)$ for 50 to $75 \mathrm{nmol} / 1$ (vitamin $\mathrm{D}$ insufficiency) and $<50 \mathrm{nmol} / \mathrm{l}$ (vitamin D deficiency), respectively $(P$, trend $=0.003)$. Mean $25(\mathrm{OH}) \mathrm{D}$ concentrations were much lower post-convalescence compared with the acute episode, regardless of case status. Compared with controls, mean VDBP was non-significantly lower in cases. We conclude that low serum $25(\mathrm{OH}) \mathrm{D}$ concentrations in DF patients predict decreased odds of progression to DHF/DSS.

Keywords: Dengue hemorrhagic fever, dengue shock syndrome, severe dengue, vitamin D, vitamin $\mathrm{D}$ binding protein.

\section{INTRODUCTION}

Dengue is one of the most rapidly spreading mosquito-borne virosis worldwide, with 50-100 million symptomatic cases each year and an annual global cost close to US $\$ 9$ billion [1-4].

A non-negligible proportion of febrile persons diagnosed with dengue infection (dengue fever, DF)

\footnotetext{
* Author for correspondence: E Villamor, Department of Epidemiology, University of Michigan School of Public Health, 1420 Washington Heights, Ann Arbor, MI 48109, USA. (Email: villamor@umich.edu)
}

progresses to severe forms of the disease, including dengue hemorrhagic fever (DHF) and dengue shock syndrome (DSS). The reasons why some patients progress to these potentially fatal forms are poorly understood. Risk factors include secondary infections by new dengue serotypes and host's genetics [5]. The host's nutritional status has been highlighted as a potentially relevant predictor of progression [6] because some nutrients exhibit strong immunomodulatory activity. Vitamin D is particularly relevant because it can modulate immunological events that have been involved in the pathophysiology of 
severe dengue [7], including downregulation of proinflammatory Th1 activity [8]. Vitamin D supplementation has been beneficial in the treatment of infections by hepatitis $\mathrm{C}$ virus, an RNA virus that shares some characteristics with dengue virus (DENV) [9].

Epidemiological evidence on the role of vitamin D on progression to severe dengue is scant. In a small cross-sectional study, among patients with secondary infections circulating total 25-hydroxy vitamin D [25(OH)D] was higher in patients with DHF than in those with DF only [10]. By contrast, concentrations of $1,25(\mathrm{OH}) \mathrm{D}$, the active form of the vitamin, were lower in Nicaraguans with DHF/DSS compared with those with DF only [11].

Identifying new potentially modifiable risk factors for progression to severe dengue disease is a critical research priority because there is no specific treatment for the infection, the therapeutic arsenal is currently very limited, and vaccination may increase hospitalization incidence in children $<9$ year-old [12]. Elucidating the role of vitamin D on severe dengue disease would constitute a critical first step to interrogate the therapeutic potential of this nutrient in patients diagnosed with DF.

We conducted a case-control study nested within a cohort of patients diagnosed with DF in Colombia who were followed during the acute episode. The primary aim was to investigate the relation of serum $25(\mathrm{OH}) \mathrm{D}$ within $96 \mathrm{~h}$ from the onset of fever with the risk of progression to DHF/DSS. We hypothesized that $25(\mathrm{OH}) \mathrm{D}$ was inversely related to the incidence of DHF/DSS. A secondary aim was to examine differences in serum total $25(\mathrm{OH}) \mathrm{D}$ concentrations between the acute episode and a post-convalescent period free of disease. Because 25(OH)D circulates bound to vitamin D binding protein (VDBP) with high affinity [13], an exploratory aim was to examine the associations of VDBP with risk of progression to DHF/DSS.

\section{METHODS}

\section{Study design}

We conducted a case-control study nested within a cohort of patients diagnosed with DF who were followed during the acute episode. We recruited febrile ambulatory patients with suspected dengue during non-epidemic (May 2003-September 2009) and epidemic (October 2009-December 2010) periods at health care centers in five areas of metropolitan
Bucaramanga, a city in northeast Colombia. Eligible participants were $\geqslant 5$ years of age and had an acute febrile syndrome caused by dengue infection with symptoms that had started $<96 \mathrm{~h}$ before consultation. At the time of recruitment, information on sociodemographic characteristics, medical history, and symptoms was elicited through a standardized interview. Height and weight were measured on calibrated instruments with the use of standardized techniques. After a physical examination, blood samples were drawn to determine albumin concentration, hematocrit, and platelet counts. We excluded patients with a history of diabetes, acquired immunodeficiency syndrome, hematologic disorders, cancer, or cardiac disease; or, at baseline, DHF or DSS (case definition below), major bleeding, hypoalbuminemia, effusions, or shock. Participants were followed daily at their homes until the 7th day of disease or the day of hospital discharge if they were admitted. Data collected included signs and symptoms, as well as daily microhematocrit measures to facilitate recognition of DHF/DSS. Platelet counts were quantified daily in patients with prior counts $<120000 / \mathrm{mm}^{3}$, or when the patient had spontaneous hemorrhage, signs of effusion, edema, or a hematocrit change $>10 \%$. Serum samples were transported to the virology laboratory at the Industrial University of Santander in Bucaramanga for storage at $-70{ }^{\circ} \mathrm{C}$. Samples were tested for dengue virus infection according to a diagnosis algorithm, which included IgM enzymelinked immunosorbent assay (ELISA) in paired sera or viral isolation, NS1 antigen detection, or RT-PCR in acute samples, with the use of methods described previously [14]. A convalescent blood sample was obtained 7-15 days after the onset of symptoms to detect $\operatorname{IgM}$ antibodies to dengue with ELISA. Dengue virus infection was defined as any of the following: viral isolation, positive NS1 antigen, or RT-PCR in acute serum $(<96 \mathrm{~h}$ from the initiation of fever); a shift from a negative to a positive IgM test result; or $\mathrm{a} \geqslant$ fourfold increase in previously existing levels of antibodies to dengue virus. Secondary dengue infection was determined with use of the Panbio dengue IgG Capture ELISA test (Alere, Australia). The test's sensitivity ranges from $81 \%$ to $96 \%$.

\section{Case definition}

Cases were patients who developed DHF or DSS during follow-up according to a modified version of the World Health Organization (WHO) 1997 criteria 
[15]. DHF cases met all the following criteria: a platelet count $\leqslant 100000 / \mathrm{mm}^{3}$, any spontaneous hemorrhage or $\geqslant 1$ positive tourniquet test, and evidence of plasma leakage (i.e. pleural effusion, ascitis, hypoalbuminemia $<4 \mathrm{~g} / \mathrm{dl}$, or a change in hematocrit from the previous assessment $>10 \%$ ). A hemoconcentration of $10 \%$, instead of $20 \%$, was chosen because this criterion has greater sensitivity in identifying dengue-related complications [16] and has been associated with vascular permeability [17]. DSS cases had all criteria above plus any reading of median blood pressure $<70 \mathrm{mmHg}$ or pulse pressure $<20 \mathrm{mmHg}$ during follow-up.

All participants provided written informed consent before enrollment into the study. Among children, written consent was sought from the primary care provider and assent from the children was confirmed before recruitment. The study protocol was approved by the Medical Ethics Committee of the Industrial University of Santander. The University of Michigan Health Sciences and Behavioral Sciences Institutional Review Board approved the use of data and samples from the study. The authors assert that all procedures contributing to this work comply with the ethical standards of the relevant national and institutional committees on human experimentation and with the Helsinki Declaration of 1975, as revised in 2008.

\section{Study population}

We recruited 820 participants into the cohort. Of them, $173(21 \cdot 1 \%)$ developed DHF/DSS during follow-up. For this case-control study, we selected all the cases that had a serum sample collected within $96 \mathrm{~h}$ from the onset of fever ('acute' serum sample, $n$ $=110,63 \cdot 6 \%$ ). Next, we randomly selected a group of controls among the patients who did not develop DHF/DSS, using a $2: 1$ ratio of controls per case plus an additional $10 \%$ in anticipation of losses due to lack of an acute serum sample. The final number of controls was 235. Selected controls were comparable to non-selected non-cases with regard to sex, age, socioeconomic status, month of infection, hours with fever before consultation, and signs of severity at the first visit. Nevertheless, compared with nonselected non-cases, selected controls were more likely to have become infected during the epidemic period and were taller and heavier. Selected cases compared with non-selected cases in the same manner as controls.
A post-convalescence blood sample was obtained in a subgroup of 15 cases and 30 controls who were visited at home after a median 1.8 years (range 1.3-2.5) from the acute episode.

\section{Laboratory methods}

\section{5-hydroxy vitamin $D$}

Samples were shipped frozen to the USA for vitamin D analyses. Serum total $25(\mathrm{OH}) \mathrm{D}$, a valid biomarker of vitamin D status, was quantified at Heartland Assays, Ames, IA with the use of the DiaSorin LIAISON 25-OH Vitamin D Total assay (Diasorin, Inc, Stillwater, Minnesota) [18, 19], a direct competitive chemiluminescence immunoassay co-specific for 25-hydroxyvitamin $\mathrm{D}_{3}$ and $\mathrm{D}_{2}$. The assay's sensitivity is $6.26 \mathrm{nmol} / 1$ and the inter-and intra-assay $\mathrm{CVs}$ are $11 \cdot 2 \%$ and $8 \cdot 1 \%$, respectively. Recovery of endogenous $25(\mathrm{OH}) \mathrm{D}$ is $100 \%$ [20].

\section{Vitamin D-binding protein}

In a subgroup of 17 DHF/DSS cases and 44 controls with available sample volumes, we quantified VDBP with the use of a Quantikine ELISA kit (R\&D Systems, Inc. Minneapolis, MN) at the Centre for Chemical Genomics, University of Michigan. The mean $\mathrm{CV}$ for replicate measures was $13 \cdot 2 \%$.

\section{Cytokines}

We determined concentrations of pro- and antiinflammatory cytokines that may be independent predictors of progression to DHF/DSS. Interferon (IFN)- $\gamma$, interleukin (IL)-10, IL-6, and tumor necrosis factor (TNF)- $\alpha$ were measured at the University of Michigan Cancer Centre Immunology Core with the use of Luminex assays (Thermo Fisher Scientific Inc. Waltham, MA). Intra-assay and inter-assay CVs were, respectively, $1 \cdot 1 \%$ and $9 \cdot 9 \%$ for IFN $\gamma ; 0 \cdot 6 \%$ and $6.2 \%$ for IL-10; $0 \cdot 4 \%$ and $7 \cdot 2 \%$ for IL-6; and $0.8 \%$ and $6.3 \%$ for $\mathrm{TNF} \alpha$.

\section{DENV virus serotype}

DENV serotypes were identified in a subsample of 29 cases and 49 controls using conventional and real time RT-PCR assays. Viral RNA was isolated from serum using the commercial kit QIAamp ${ }^{\mathbb{R}}$ Viral RNA (QIAGEN). Conventional RT-PCR tests were performed following the Lanciotti protocol [21]. Real time RT-PCRs were conducted with the CDC Kit 
DENV-1-4 Real-Time RT-PCR [22] (CDC, Puerto Rico, USA). Positive and negative controls were included in each test.

\section{Data analysis}

Vitamin D serostatus and progression to DHF/DSS

We first compared the distribution of baseline characteristics between DHF/DSS cases and controls. Sociodemographic, anthropometric, clinical, virological, and immunological variables were categorized as presented in Table 1. Case-control differences were tested with the use of $\chi^{2}$ and Wilcoxon Rank-Sum tests for categorical and continuous characteristics, respectively. Next, we examined the associations of baseline covariates with the primary exposure, $25(\mathrm{OH}) \mathrm{D}$, among controls. The distribution of background characteristics was compared across conventional $25(\mathrm{OH}) \mathrm{D}$ status categories [23] $\geqslant 75$ (sufficient), 50 to $<75$ (insufficient), or $<50 \mathrm{nmol} / 1$ (deficient). Using a lower cutpoint to characterize deficiency (e.g. $<30 \mathrm{nmol} / \mathrm{l}$ ) was not feasible due to the small number of participants with $25(\mathrm{OH}) \mathrm{D}$ concentrations below this value. We used Cochran-Armitage tests for trend for dichotomous variables and a Wald test for a linear term representing $25(\mathrm{OH}) \mathrm{D}$ categories in linear regression models for continuous covariates.

To examine the association of $25(\mathrm{OH}) \mathrm{D}$ with $\mathrm{DHF} /$ DSS, we compared the odds of exposure to $25(\mathrm{OH}) \mathrm{D}$ status categories between cases and controls with the use of unconditional logistic regression. Adjusted odds ratios (OR) with 95\% confidence intervals (CI) were estimated from multivariable logistic regression with covariates that were associated with case status or related to $25(\mathrm{OH}) \mathrm{D}$ at $P<0.10$ and remained significant in the model at $P<0.05$ or that were considered relevant from a biological viewpoint. Because in a previous cross-sectional study the relation between 25(OH)D and DHF was restricted to patients with secondary infections [10], we examined whether type of infection modified the association of $25(\mathrm{OH})$ $\mathrm{D}$ and DHF/DSS, through stratification. The statistical significance of the interaction was tested with use of the likelihood ratio test.

Change in vitamin D status from the acute episode to post-convalescence

In the subgroup of 15 DHF/DSS cases and 30 controls with a post-convalescence blood sample, we estimated the difference in total $25(\mathrm{OH}) \mathrm{D}$ concentrations between after $>1$ year of recovery and the acute episode. We used a repeated measures linear regression model with $25(\mathrm{OH}) \mathrm{D}$ as a continuous outcome and order of measurement, sex, age at the time of the acute episode, and month of sample collection as predictors. An unstructured covariance matrix was specified to account for within-subject correlations. Analyses were conducted separately for cases and controls and for both groups combined. Participants with a post-convalescence sample were more likely to have been recruited during the epidemic period, were younger and of lower socioeconomic status, and consulted later after the onset of fever than those without these samples. They did not differ with respect to baseline 25(OH)D levels or other variables.

\section{VDBP in relation to $D H F / D S S$}

We compared the distribution of VDBP between 17 cases and 44 controls using Wilcoxon Rank-Sum tests. The subset of participants with these measurements did not differ from the rest with respect to total $25(\mathrm{OH}) \mathrm{D}$ concentrations or any of the baseline characteristics measured.

All analyses were carried out with Statistical Analysis Software version 9.4 (SAS Institute Inc. Cary, NC).

\section{RESULTS}

\section{Characteristics of cases and controls}

Half of participants were women $(n=174)$; mean \pm S.D. age was $26 \cdot 6 \pm 15 \cdot 2$ years (range: $5-86$ ), $24 \cdot 9 \%$ were $<15$ years. Compared with controls, cases were significantly older, consulted earlier after the onset of fever, had lower platelet counts, and had higher concentrations of IL-10 and IL-6 (Table 1). Most cases occurred during the endemic period and during the months of March/April. In the subgroup with information on DENV serotype, the ratios of controls to cases for serotypes 1, 2, 3, and 4 were, respectively, $17: 3,4: 10,17: 12$, and $11: 4$. Cases did not differ significantly from controls with respect to other baseline characteristics.

\section{Correlates of 25(OH)D}

Among controls, 25(OH)D was inversely associated with female sex and age (Table 2). Associations with 
Table 1. Characteristics of dengue fever controls and dengue hemorrhagic fever/dengue shock syndrome cases at the initial clinic visit

\begin{tabular}{|c|c|c|c|}
\hline Characteristics & $\begin{array}{l}\text { Controls } \\
n=235\end{array}$ & $\begin{array}{l}\text { Cases } \\
n=110\end{array}$ & $P^{\mathrm{a}}$ \\
\hline \multicolumn{4}{|l|}{ Sociodemographic and anthropometric (\%) } \\
\hline Male sex & $50 \cdot 2$ & $48 \cdot 2$ & 0.73 \\
\hline Age $<15$ years & $29 \cdot 8$ & $14 \cdot 6$ & 0.002 \\
\hline Low socioeconomic status ${ }^{\mathrm{b}}$ & $33 \cdot 2$ & $33 \cdot 9$ & $0 \cdot 89$ \\
\hline Short stature $^{c}$ & $12 \cdot 6$ & $15 \cdot 1$ & 0.53 \\
\hline Obesity $^{\mathrm{d}}$ & $8 \cdot 5$ & $9 \cdot 4$ & $0 \cdot 77$ \\
\hline \multicolumn{4}{|l|}{ Clinical (\%) } \\
\hline Episode in the epidemic period & $38 \cdot 3$ & $23 \cdot 6$ & $0 \cdot 007$ \\
\hline Episode in March/April ${ }^{\mathrm{e}}$ & $15 \cdot 3$ & $35 \cdot 5$ & $<0.0001$ \\
\hline$\geqslant 72 \mathrm{~h}$ with fever before consultation & $65 \cdot 5$ & $55 \cdot 5$ & $0 \cdot 07$ \\
\hline Spontaneous hemorrhage & 8.9 & $9 \cdot 1$ & 0.96 \\
\hline Orthostatic hypotension & $12 \cdot 3$ & $16 \cdot 4$ & $0 \cdot 31$ \\
\hline Tourniquet test positive & $39 \cdot 5$ & $48 \cdot 6$ & $0 \cdot 11$ \\
\hline Thrombocytopenia $^{\mathrm{f}}$ & $14 \cdot 9$ & $50 \cdot 6$ & $<0 \cdot 0001$ \\
\hline Hematocrit $\%$, (mean \pm s.D. $)$ & $41 \cdot 8 \pm 4 \cdot 4$ & $41 \cdot 7 \pm 4 \cdot 7$ & $0 \cdot 61$ \\
\hline \multicolumn{4}{|l|}{ Virological (\%) } \\
\hline Secondary infection & $27 \cdot 2$ & $27 \cdot 6$ & 0.94 \\
\hline Serotype 2 or $3^{\mathrm{g}}$ & $42 \cdot 9$ & $75 \cdot 9$ & $0 \cdot 005$ \\
\hline \multicolumn{4}{|l|}{ Immunological (mean \pm s.D.) } \\
\hline Interferon-gamma $(\mathrm{pg} / \mathrm{ml})$ & $41 \cdot 8 \pm 53 \cdot 5$ & $53 \cdot 0 \pm 64 \cdot 7$ & $0 \cdot 15$ \\
\hline Interleukin-10 (pg/ml) & $138 \cdot 4 \pm 211 \cdot 5$ & $205 \cdot 3 \pm 253 \cdot 1$ & $0 \cdot 0001$ \\
\hline Interleukin-6 (pg/ml) & $4 \cdot 9 \pm 9 \cdot 8$ & $5 \cdot 1 \pm 3 \cdot 6$ & $<0.0001$ \\
\hline Tumor necrosis factor- $\alpha(\mathrm{pg} / \mathrm{ml})$ & $14 \cdot 7 \pm 8 \cdot 8$ & $16 \cdot 6 \pm 10 \cdot 6$ & $0 \cdot 14$ \\
\hline
\end{tabular}

${ }^{a} \chi^{2}$ and Wilcoxon Rank-Sum tests for dichotomous and continuous characteristics, respectively.

${ }^{\mathrm{b}}$ Strata 1 and 2 (out of 5) of the local government's socioeconomic status classification of households for tax and planning purposes.

${ }^{\mathrm{c}}$ For participants $<18$ years of age, height-for-age $Z$ score $<-1$ according to the World Health Organization sex-specific growth reference for school-aged children and adolescents [38]. For participants $\geqslant 18$ years of age, height $<-1 Z$ of the sex-specific distributions of controls $(<151 \mathrm{~cm}$ for women and $<167 \mathrm{~cm}$ for men).

${ }^{\mathrm{d}}$ For participants $<18$ years of age, BMI-for-age $\geqslant 2 Z$ according to the World Health Organization sex-specific growth reference for school-aged children and adolescents. For participants $\geqslant 18$ years of age, BMI $\geqslant 30 \mathrm{~kg} / \mathrm{m}^{2}$.

${ }^{\mathrm{e}}$ Months with highest average annual ultraviolet $\mathrm{B}$ radiation in the city $\left(11\right.$ and $10.5 \mathrm{~mW} / \mathrm{cm}^{2} \mathrm{~nm}$ in March and April, respectively, $v s .<10 \mathrm{~mW} / \mathrm{cm}^{2} \mathrm{~nm}$ in any other month).

${ }^{\mathrm{f}}$ Platelet count $<100000 / \mathrm{mm}^{3}$.

${ }^{g}$ DENV serotyping was conducted in a subsample of 49 controls and 29 cases.

other baseline characteristics were not statistically significant.

\section{5(OH)D and progression to DHF/DSS}

Mean \pm s.D. $25(\mathrm{OH}) \mathrm{D}(\mathrm{nmol} / \mathrm{l})$ did not differ significantly between controls $(95.3 \pm 25.8)$ and cases $(93.1 \pm 19.7)(P=0.73)$. Nevertheless, the odds of exposure to vitamin D insufficiency or deficiency were significantly lower in cases than they were in controls (Table 3). Compared with vitamin D concentrations $\geqslant 75 \mathrm{nmol} / 1$, OR $(95 \% \mathrm{CI})$ for vitamin $\mathrm{D}$ insufficiency and deficiency were, respectively,
$0 \cdot 44(0 \cdot 22,0 \cdot 88)$ and $0 \cdot 13(0 \cdot 02,1 \cdot 05)(P$, test for trend $=0.003)$ after adjustment for sex, age, hours with fever before consultation, and IL-10 concentrations. The association did not differ between patients with primary and secondary infections $(P$, test for interaction $=0 \cdot 45$ ).

\section{Change in vitamin D status from the acute episode to post-convalescence}

Among the 45 participants with post-convalescence sera, total $25(\mathrm{OH}) \mathrm{D}$ concentrations were an adjusted $16.8 \mathrm{nmol} / 1$ lower than they were at the onset of the 
Table 2. Serum total 25-hydroxy vitamin D concentrations according to baseline characteristics among dengue fever controls

\begin{tabular}{|c|c|c|c|c|}
\hline \multirow[b]{2}{*}{ Characteristics } & \multicolumn{3}{|c|}{ Serum total 25 -hydroxy vitamin D (nmol/l) } & \multirow[b]{2}{*}{$P^{\mathrm{a}}$} \\
\hline & $\begin{array}{l}\geqslant 75 \\
n=180\end{array}$ & $\begin{array}{l}50 \text { to }<75 \\
n=46\end{array}$ & $\begin{array}{l}<50 \\
n=9\end{array}$ & \\
\hline Serum total $25(\mathrm{OH}) \mathrm{D}$ (mean \pm s.D.) & $104 \cdot 8 \pm 21 \cdot 4$ & $67 \cdot 7 \pm 6 \cdot 1$ & $47 \cdot 4 \pm 2 \cdot 0$ & \\
\hline \multicolumn{5}{|l|}{ Sociodemographic and anthropometric $(\%)$} \\
\hline Male sex & $58 \cdot 9$ & $23 \cdot 9$ & $11 \cdot 1$ & $<0 \cdot 0001$ \\
\hline Age $<15$ years & $35 \cdot 0$ & $15 \cdot 2$ & $0 \cdot 0$ & $0 \cdot 001$ \\
\hline Low socioeconomic status ${ }^{\mathrm{b}}$ & $32 \cdot 8$ & $34 \cdot 8$ & $33 \cdot 3$ & $0 \cdot 84$ \\
\hline Short stature ${ }^{\mathrm{c}}$ & $11 \cdot 5$ & $15 \cdot 0$ & $22 \cdot 2$ & $0 \cdot 29$ \\
\hline Obesity $^{\mathrm{d}}$ & $6 \cdot 7$ & $15 \cdot 0$ & $11 \cdot 1$ & $0 \cdot 15$ \\
\hline \multicolumn{5}{|l|}{ Clinical $(\%)$} \\
\hline Episode in the epidemic period & $37 \cdot 8$ & $41 \cdot 3$ & $33 \cdot 3$ & $0 \cdot 90$ \\
\hline Episode in March/April ${ }^{\mathrm{e}}$ & $16 \cdot 1$ & $13 \cdot 0$ & $11 \cdot 1$ & $0 \cdot 53$ \\
\hline$\geqslant 72 \mathrm{~h}$ with fever before consultation & $67 \cdot 8$ & $58 \cdot 7$ & $55 \cdot 6$ & $0 \cdot 20$ \\
\hline Spontaneous hemorrhage & $10 \cdot 6$ & $4 \cdot 4$ & $0 \cdot 0$ & $0 \cdot 11$ \\
\hline Orthostatic hypotension & $11 \cdot 1$ & $17 \cdot 4$ & $11 \cdot 1$ & $0 \cdot 43$ \\
\hline Tourniquet test positive & $37 \cdot 2$ & $43 \cdot 2$ & $66 \cdot 7$ & $0 \cdot 09$ \\
\hline Thrombocytopenia ${ }^{\mathrm{f}}$ & $14 \cdot 5$ & $11 \cdot 4$ & $37 \cdot 5$ & $0 \cdot 36$ \\
\hline Hematocrit $\%$ (mean \pm s.D. $)$ & $41 \cdot 8 \pm 4 \cdot 2$ & $42 \cdot 0 \pm 4 \cdot 9$ & $40 \cdot 9 \pm 5 \cdot 7$ & $0 \cdot 87$ \\
\hline \multicolumn{5}{|l|}{ Virological $(\%)$} \\
\hline Secondary infection & $27 \cdot 3$ & $25 \cdot 6$ & $33 \cdot 3$ & $0 \cdot 91$ \\
\hline Serotype 2 or $3^{\mathrm{g}}$ & $40 \cdot 5$ & $50 \cdot 0$ & - & $0 \cdot 57$ \\
\hline \multicolumn{5}{|l|}{ Immunological (mean \pm s.D.) } \\
\hline Interferon-gamma (pg/ml) & $42 \cdot 3 \pm 57 \cdot 2$ & $38 \cdot 0 \pm 36 \cdot 1$ & $51 \cdot 0 \pm 54 \cdot 1$ & $0 \cdot 94$ \\
\hline Interleukin-10 $(\mathrm{pg} / \mathrm{ml})$ & $145 \cdot 5 \pm 222 \cdot 9$ & $97 \cdot 7 \pm 111 \cdot 4$ & $204 \cdot 6 \pm 334 \cdot 4$ & $0 \cdot 59$ \\
\hline Interleukin- $6(\mathrm{pg} / \mathrm{ml})$ & $5 \cdot 2 \pm 11 \cdot 1$ & $3 \cdot 9 \pm 2 \cdot 8$ & $4 \cdot 7 \pm 3 \cdot 0$ & $0 \cdot 48$ \\
\hline Tumor necrosis factor- $\alpha(\mathrm{pg} / \mathrm{ml})$ & $14 \cdot 4 \pm 8 \cdot 6$ & $15 \cdot 4 \pm 9 \cdot 2$ & $17 \cdot 3 \pm 10 \cdot 3$ & $0 \cdot 26$ \\
\hline
\end{tabular}

$\overline{~ a ~ C o c h r a n-A r m i t a g e ~ t e s t ~ f o r ~ t r e n d ~ f o r ~ d i c h o t o m o u s ~ c h a r a c t e r i s t i c s . ~ F o r ~ c o n t i n u o u s ~ c h a r a c t e r i s t i c s, ~ t e s t ~ f o r ~ l i n e a r ~ t r e n d ~ w h e n ~ a ~}$ variable representing vitamin D categories was introduced into a linear regression model as a continuous predictor.

${ }^{\mathrm{b}}$ Strata 1 and 2 (out of 5) of the local government's socioeconomic status classification of households for tax and planning purposes.

${ }^{\mathrm{c}}$ For participants $<18$ years of age, height-for-age $Z$ score $<-1$ according to the World Health Organization sex-specific growth reference for school-aged children and adolescents [38]. For participants $\geqslant 18$ years of age, height $<-1 Z$ of the sex-specific distributions of controls $(<151 \mathrm{~cm}$ for women and $<167 \mathrm{~cm}$ for men).

${ }^{\mathrm{d}}$ For participants $<18$ years of age, BMI-for-age $\geqslant 2 Z$ according to the World Health Organization sex-specific growth reference for school-aged children and adolescents. For participants $\geqslant 18$ years of age, BMI $\geqslant 30 \mathrm{~kg} / \mathrm{m}^{2}$.

${ }^{\mathrm{e}}$ Highest average annual ultraviolet $\mathrm{B}$ radiation in the region $\left(11\right.$ and $10.5 \mathrm{~mW} / \mathrm{cm}^{2} \mathrm{~nm}$ in March and April, respectively, $v s$. $<10 \mathrm{~mW} / \mathrm{cm}^{2} \mathrm{~nm}$ in any other month).

${ }^{\mathrm{f}}$ Platelet count $<100000 / \mathrm{mm}^{3}$.

${ }^{\mathrm{g}}$ DENV serotyping was conducted in a subsample of 49 controls and 29 cases.

acute episode $(P<0 \cdot 0001)$ (Table 4). The decline was comparable between cases and controls.

\section{VDBP and progression to DHF/DSS}

Mean \pm s.D. VDBP was higher in controls $(5733 \pm$ $2424 \mathrm{nmol} / \mathrm{l})$ compared with cases $(5175 \pm 3470$ $\mathrm{nmol} / \mathrm{l})$, but the difference was not statistically significant $(P=0 \cdot 18)$.

\section{DISCUSSION}

In this case-control study of DF patients, lower vitamin D serostatus at the onset of fever was associated with decreased odds of progression to DHF/DSS. 25 $(\mathrm{OH}) \mathrm{D}$ concentrations decreased markedly from the time of the acute episode to $>1$ year post-convalescence in both cases and controls. VDBP was lower in cases than among controls, although this difference was not statistically significant. 
Table 3. Vitamin D status at the time of consultation for the acute episode and progression to dengue hemorrhagic fever/dengue shock syndrome

\begin{tabular}{|c|c|c|c|c|}
\hline & \multicolumn{3}{|c|}{ Serum total 25 -hydroxy vitamin D (nmol/l) } & \multirow[b]{2}{*}{$P^{\mathrm{a}}$} \\
\hline & $\geqslant 75$ & 50 to $<75$ & $<50$ & \\
\hline Ratio of controls to cases & $180: 96$ & $46: 13$ & $9: 1$ & \\
\hline \multicolumn{5}{|l|}{ Odds ratio $(95 \% \text { confidence interval })^{\mathrm{b}}$} \\
\hline Unadjusted & $1 \cdot 00$ & $0 \cdot 53(0 \cdot 27-1 \cdot 03)$ & $0 \cdot 21(0 \cdot 03-1 \cdot 67)$ & $0 \cdot 02$ \\
\hline Sex and age-adjusted & $1 \cdot 00$ & $0 \cdot 44(0 \cdot 22-0 \cdot 87)$ & $0 \cdot 15(0 \cdot 02-1 \cdot 24)$ & $0 \cdot 004$ \\
\hline Multivariable-adjusted $^{\mathrm{c}}$ & $1 \cdot 00$ & $0 \cdot 44(0 \cdot 22-0 \cdot 88)$ & $0 \cdot 13(0 \cdot 02-1 \cdot 05)$ & $0 \cdot 003$ \\
\hline
\end{tabular}

${ }^{\mathrm{a}}$ Test for trend when a variable representing ordinal categories of $25(\mathrm{OH}) \mathrm{D}$ concentrations was introduced into the logistic regression model as a continuous predictor.

${ }^{\mathrm{b}}$ From unconditional logistic regression.

${ }^{\mathrm{c}}$ Adjusted for sex ( 1 indicator variable), age $<15$ years ( 1 indicator), $\geqslant 72 \mathrm{~h}$ with fever before consultation ( 1 indicator), and serum interleukin-10 (continuous).

Table 4. Differences in serum 25-hydroxy vitamin D between the time of consultation for the acute episode and $>1$ year post-convalescence

\begin{tabular}{llll}
\hline \hline Serum 25-hydroxy vitamin D (nmol/l) & $\begin{array}{l}\text { Controls } \\
n=30\end{array}$ & $\begin{array}{l}\text { Cases } \\
n=15\end{array}$ & $\begin{array}{l}\text { All } \\
n=45\end{array}$ \\
\hline Acute episode (mean \pm S.D.) & $92 \cdot 2 \pm 21 \cdot 6$ & $93 \cdot 1 \pm 17 \cdot 2$ & $92 \cdot 5 \pm 20 \cdot 0$ \\
Post-convalescence (mean \pm s.D.) & $71 \cdot 9 \pm 15 \cdot 5$ & $71 \cdot 7 \pm 14 \cdot 7$ & $71 \cdot 8 \pm 15 \cdot 1$ \\
Unadjusted mean difference $\left(95 \%\right.$ CI) $^{\mathrm{a}}$ & $-20 \cdot 4(-25 \cdot 7$ to $-15 \cdot 0)$ & $-21 \cdot 4(-28 \cdot 2$ to $-14 \cdot 6)$ & $-20 \cdot 7(-24 \cdot 9$ to $-16 \cdot 5)$ \\
Adjusted mean difference $(95 \% \mathrm{CI})^{\mathrm{b}}$ & $-17 \cdot 1(-25 \cdot 2$ to $-8 \cdot 9)$ & $-16 \cdot 1(-25 \cdot 5$ to $-6 \cdot 6)$ & $-16 \cdot 8(-24 \cdot 4$ to $-9 \cdot 2)$ \\
\hline \hline
\end{tabular}

${ }^{\text {a }}$ From a repeated measurements linear regression model with an unstructured covariance matrix to account for the intrasubject correlation of measurements.

${ }^{\mathrm{b}}$ Adjusted for sex, age $<15$ years at the time of the acute episode, and month of measurement.

Although contrary to our hypothesis, the positive association between total $25(\mathrm{OH}) \mathrm{D}$ concentrations and incidence of DHF/DSS is a novel finding. This question had only been addressed in a cross-sectional study in India, in which mean $25(\mathrm{OH}) \mathrm{D}$ concentrations were non-significantly higher in 38 patients with DHF compared with 45 DF controls [10]. Potential explanatory mechanisms remain speculative. Vitamin $\mathrm{D}$ has been related to a decreased antiinflammatory IL-10 response to viral toll-like receptor-3 stimulation [24]. In addition, some [25] albeit not all [26] - studies of intracellular infections have suggested that vitamin D may increase dendritic cell expression of CD209, a dengue virus receptor. This could, in theory, enhance cellular susceptibility to infection, viral replication, and inflammation. A different mechanistic path could involve expression of the vitamin D receptor (VDR) in immune cells. Some studies have found associations between VDR genetic polymorphisms and risk of progression to severe dengue [27-29], but whether VDR expression differs between progressors and non-progressors has not been investigated.

The association of serum total $25(\mathrm{OH}) \mathrm{D}$ with DHF/DSS should also be interpreted considering the comparison with post-convalescence concentrations. $25(\mathrm{OH}) \mathrm{D}$ levels after $>1$ year from the acute episode were markedly lower compared with those in acute sera, regardless of case status. Although the habitual baseline $25(\mathrm{OH}) \mathrm{D}$ levels of this population are unknown, the post-convalescence concentrations are closer to those previously reported for apparently healthy Colombian school children [30] than the acute episode concentrations. This finding is consistent with the cross-sectional study in India [10] in that $25(\mathrm{OH}) \mathrm{D}$ concentrations of healthy controls were much lower than those of patients with DF or DHF. This 'gradient' of lower, middle, and higher $25(\mathrm{OH}) \mathrm{D}$ concentrations for people without dengue infection, with DF only, and with DHF/DSS, 
respectively, raises the possibility that the infection elicits an acute increase in circulating vitamin D as part of the body's defense response. Eighty-eight percent of 25(OH)D circulates bound to VDBP with high affinity, another $12 \%$ circulates bound to albumin with lower affinity, and only $0.03 \%$ is unbound and considered free vitamin D [13]. Bioavailable vitamin $\mathrm{D}$ is the fraction unbound to VDBP; thus, increasing vitamin $\mathrm{D}$ bioavailability as part of a defense response should occur through enhancing the $25(\mathrm{OH}) \mathrm{D}$ fraction unbound to VDBP and this might happen by decreasing VDBP. Consistent with this possibility, in our study DHF/DSS cases had lower VDBP than controls, even though this difference was not statistically significant. Circulating VDBP might decrease in patients with severe dengue through reduced protein expression but this was not the case in one study of 10 patients [31]. An anecdotal report of five cases with DF suggested that the administration of vitamin $\mathrm{D}$ and calcium during the acute episode shortened the duration of disease [32]; thus, the potential therapeutic value of enhancing vitamin $\mathrm{D}$ bioavailability during acute dengue infection requires careful consideration in future investigations.

Our study has several strengths. Prospective collection of outcome information reduced misclassification and the use of an objective biomarker of exposure prevented recall bias. We had the possibility to consider and control for important potential confounders, including markers of inflammation. Case-control differences in known predictors of progression to severe dengue provided indirect evidence of internal validity. For example, IL-10 and IL-6 concentrations were higher in cases compared with controls, as previously reported [33]. TNF- $\alpha$ was also higher in cases than controls as expected, albeit the difference was not statistically significant possibly owing to low statistical power. We examined a subsample of participants to compare their own exposure status during a diseasefree period; this approach is stronger than using a different set of healthy controls because any differences in vitamin D status during the two periods cannot be attributed to time-invariant characteristics including genetics and some environmental exposures. We had the possibility to measure VDBP in a subsample, to generate new hypotheses.

A few limitations are also worth noting. Despite the prospective nature of data collection, reverse causation bias cannot be completely ruled out. Reverse causation could explain the results if factors that predispose progression influenced $25(\mathrm{OH}) \mathrm{D}$ concentrations before the acute sample was collected. For example, increased vascular permeability early during the infection could have resulted in protein leakage to the extravascular space with greater plasma loss of VDBP- and albumin-bound 25(OH)D in patients who would become cases than among controls. Lower VDBP concentrations in cases compared with controls would be consistent with this possibility. Early plasma leakage could also result in hemoconcentration, increasing $25(\mathrm{OH}) \mathrm{D}$ in patients who would become cases. Nevertheless, we did not find differences in baseline hematocrit between cases and controls. Early hemoconcentration during the DF episode could explain the higher $25(\mathrm{OH}) \mathrm{D}$ concentrations measured in the acute sample compared with those collected post-convalescence. Another potential limitation is selection bias, which may occur when the selection of controls is not independent of exposure status. In our study, selected controls differed from non-selected non-cases in characteristics that may be related to $25(\mathrm{OH}) \mathrm{D}$ concentrations, including body weight; thus, it is not possible to completely discard selection bias. The subsample of patients with postconvalescence samples was not comparable with the rest of participants with respect to some characteristics and statistical power to examine the association of VDBP with progression to DHF/DSS was limited. Lack of sample volume and funding constraints prevented us from determining DENV serotype in all study participants. Nevertheless, this is not a major limitation of the study because serotype was not related to vitamin D status and is therefore an unlikely source of confounding. Finally, case definition was not based on the more recent classification of dengue severity proposed by the WHO in 2009 [34]. This classification has higher sensitivity than the 1997 classification to identify patients with severe dengue that would require intensive care [35-37].

In conclusion, low total serum 25 -hydroxy vitamin $\mathrm{D}$ concentrations at the time of DF diagnosis predict decreased odds of progression to DHF/DSS. There may be differences in serum VDBP related to the severity of dengue infection. Circulating vitamin D is much higher during an acute dengue episode than during disease-free period.

\section{ACKNOWLEDGEMENTS}

This work was supported by the Global Health Office at the University of Michigan School of Public Health, the National Institute of Allergy and 
Infectious Diseases (E.V., R21AI103364), and the Colombian Administrative Department of Science, Technology, and Innovation - Colciencias (L.A.V., grants numbers 1102-04-12919, 1102-04-18205, and 1102-459-21561).

\section{DECLARATION OF INTEREST}

None.

\section{REFERENCES}

1. Shepard DS, et al. The global economic burden of dengue: a systematic analysis. Lancet Infectious Diseases 2016; 16: 935-941.

2. L'Azou M, et al. Symptomatic dengue in children in 10 Asian and Latin American Countries. New England Journal of Medicine 2016; 374: 1155-1166.

3. Wilson ME, Chen LH. Dengue: update on epidemiology. Current Infectious Disease Reports 2015; 17: 457.

4. Bhatt S, et al. The global distribution and burden of dengue. Nature 2013; 496: 504-507.

5. Guzman MG, Alvarez M, Halstead SB. Secondary infection as a risk factor for dengue hemorrhagic fever/dengue shock syndrome: an historical perspective and role of antibody-dependent enhancement of infection. Archives of Virology 2013; 158: 1445-1459.

6. Ahmed S, et al. Micronutrients and dengue. American Journal of Tropical Medicine and Hygiene 2014; 91: 1049-1056.

7. Arboleda JF, Urcuqui-Inchima S. Vitamin D-regulated microRNAs: are they protective factors against dengue virus infection? Advances in Virology 2016; 2016: 1016840.

8. Aranow C. Vitamin D and the immune system. Journal of Investigative Medicine 2011; 59: 881-886.

9. Eltayeb AA, et al. Vitamin D status and viral response to therapy in hepatitis $\mathrm{C}$ infected children. World Journal of Gastroenterology 2015; 21: 1284-1291.

10. Alagarasu K, et al. Elevated levels of vitamin D and deficiency of mannose binding lectin in dengue hemorrhagic fever. Virology Journal 2012; 9: 86.

11. Voge NV, et al. Metabolomics-based discovery of small molecule biomarkers in serum associated with dengue virus infections and disease outcomes. PLoS Neglected Tropical Diseases 2016; 10: e0004449.

12. Hadinegoro SR, et al. Efficacy and long-term safety of a dengue vaccine in regions of endemic disease. New England Journal of Medicine 2015; 373: 1195-1206.

13. Bikle DD, et al. Assessment of the free fraction of 25-hydroxyvitamin $\mathrm{D}$ in serum and its regulation by albumin and the vitamin D-binding protein. Journal of Clinical Endocrinology and Metabolism 1986; 63: 954-959.

14. Villar-Centeno LA, Diaz-Quijano FA, Martinez-Vega RA. Biochemical alterations as markers of dengue hemorrhagic fever. American Journal of Tropical Medicine and Hygiene 2008; 78: 370-374.
15. World Health Organization. Dengue Haemorrhagic Fever: Diagnosis, Treatment, Prevention and Control, 2nd edn. Geneva, Switzerland: WHO, 1997.

16. Rigau-Perez JG, Bonilla GL. An evaluation of modified case definitions for the detection of dengue hemorrhagic fever. Puerto Rico Association of Epidemiologists. Puerto Rico Health Sciences Journal 1999; 18: 347-352.

17. Diaz-Quijano FA, Martinez-Vega RA, Villar-Centeno LA. [Early indicators of severity in dengue virus infection]. Enfermedades Infecciosas y Microbiología Clínica 2005; 23: 529-532.

18. Ersfeld DL, et al. Analytical and clinical validation of the $25 \mathrm{OH}$ vitamin D assay for the LIAISON automated analyzer. Clinical Biochemistry 2004; 37: 867-874.

19. Wagner D, Hanwell HE, Vieth R. An evaluation of automated methods for measurement of serum 25-hydroxyvitamin D. Clinical Biochemistry 2009; 42: 1549-1556.

20. Horst RL. Exogenous versus endogenous recovery of 25-hydroxyvitamins D2 and D3 in human samples using high-performance liquid chromatography and the DiaSorin LIAISON total-D assay. Journal of Steroid Biochemistry and Molecular Biology 2010; 121: 180-182.

21. Lanciotti RS, et al. Rapid detection and typing of dengue viruses from clinical samples by using reverse transcriptase-polymerase chain reaction. Journal of Clinical Microbiology 1992; 30: 545-551.

22. Santiago GA, et al. Analytical and clinical performance of the CDC real time RT-PCR assay for detection and typing of dengue virus. PLoS Neglected Tropical Diseases 2013; 7: e2311.

23. Holick MF. The vitamin D epidemic and its health consequences. Journal of Nutrition 2005; 135: 2739S-2748S.

24. Liao SL, et al. Maternal vitamin D level Is associated with viral toll-like receptor triggered IL-10 response but not the risk of infectious diseases in infancy. Mediators of Inflammation 2016; 2016: 8175898.

25. Torres C, et al. Immunophenotype of vitamin D receptor polymorphism associated to risk of HIV-1 infection and rate of disease progression. Current HIV Research 2010; 8: 487-492.

26. Afsal K, Selvaraj P. Effect of 1,25-dihydroxyvitamin D3 on the expression of mannose receptor, DC-SIGN and autophagy genes in pulmonary tuberculosis. Tuberculosis 2016; 99: 1-10.

27. Dettogni RS, et al. Single nucleotide polymorphisms in immune system genes and their association with clinical symptoms persistence in dengue-infected persons. Human Immunology 2015; 76: 717-723.

28. Alagarasu K, et al. Association of vitamin D receptor gene polymorphisms with clinical outcomes of dengue virus infection. Human Immunology 2012; 73: 1194-1199.

29. Loke H, et al. Susceptibility to dengue hemorrhagic fever in Vietnam: evidence of an association with variation in the vitamin $\mathrm{d}$ receptor and $\mathrm{Fc}$ gamma receptor IIa genes. American Journal of Tropical Medicine and Hygiene 2002; 67: 102-106.

30. Thornton KA, et al. Vitamin D deficiency associated with increased incidence of gastrointestinal and ear 
infections in school-age children. Pediatric Infectious Disease Journal 2013; 32: 585-593.

31. Fragnoud R, et al. Isotope coded protein labeling analysis of plasma specimens from acute severe dengue fever patients. Proteome Science 2012; 10: 60.

32. Sanchez-Valdez E, et al. Clinical response in patients with dengue fever to oral calcium plus vitamin D administration: study of 5 cases. Proceedings of the Western Pharmacology Society 2009; 52: 14-17.

33. John DV, Lin YS, Perng GC. Biomarkers of severe dengue disease - a review. Journal of Biomedical Science 2015; 22: 83.

34. World Health Organization. Dengue: Guidelines for Diagnosis, Treatment, Prevention and Control. Geneva, Switzerland: WHO, 2009.
35. Alexander $\mathbf{N}$, et al. Multicentre prospective study on dengue classification in four South-east Asian and three Latin American countries. Tropical Medicine \& International Health 2011; 16: 936-948.

36. Narvaez F, et al. Evaluation of the traditional and revised WHO classifications of dengue disease severity. PLoS Neglected Tropical Diseases 2011; 5: e1397.

37. Macedo GA, et al. Sensitivity and specificity of the World Health Organization dengue classification schemes for severe dengue assessment in children in Rio de Janeiro. PLoS ONE 2014; 9: e96314.

38. de Onis M, et al. Development of a WHO growth reference for school-aged children and adolescents. Bulletin of the World Health Organization 2007; 85: 660-667. 